\title{
Orthorectification and Pan-Sharpening of WorldView-2 Satellite Imagery to Produce High Resolution Coloured Ortho-Photos
}

\author{
Oscar Rosario Belfiore ${ }^{1} \&$ Claudio Parente ${ }^{1}$ \\ ${ }^{1}$ Department of Sciences and Technologies, University of Naples "Parthenope", Naples, Italy \\ Correspondence: Claudio Parente, Department of Sciences and Technologies, University of Naples \\ "Parthenope", Centro Direzionale Is. C4, Naples, Italy. Tel: 39-815-476-608. E-mail: \\ claudio.parente@uniparthenope.it
}

Received: February 9, 2015

Accepted: February 20, $2015 \quad$ Online Published: August 30, 2015

doi:10.5539/mas.v9n9p122

URL: http://dx.doi.org/10.5539/mas.v9n9p122

The research is financed by MIUR (Ministero dell'Istruzione, dell'Università e della Ricerca), the Italian Ministry of Instruction, University and Research, through the fund PRIN 2010-11.

\begin{abstract}
In the last decade VHR (Very High Resolution) images from satellite, because of the reduced dimensions of pixel (less than 1 meter) and the availability in different acquisition bands ( 4 or more), have had major dffusion in many application fields of remote sensing. They can be used also to produce high resolution coloured ortho-photos, but adequate levels of positional accuracy as well as small pixel dimensions are necessary. The aim of this paper is to demonstrate that WorldView-2 (WV-2) images satisfy totally these requirements if firstly submitted to high accurate rectification and Pan-Sharpening processes. Using Rational Polynomial Functions (RPFs), original dataset can be better overlapped to cartographic maps at medium or great scale; multispectral images (cell size: $2 \mathrm{~m}$ ) can be resampled to meet geometric resolution of pan one (cell size: $0.5 \mathrm{~m}$ ), so detailed and attendible RGB composition results. Applications are carried out on one sample of WV-2 imagery concerning a scene within the Province of Caserta (Italy) that includes vegetated as well as urban areas. Finally RGB composition with pixel dimensions of $0.5 \mathrm{~m}$, positional accuracy less than 1 meter and likely colors are achieved, confirming the possibility to use this type of images for coloured ortho-photos at scale 1:5.000 at least.
\end{abstract}

Keywords: worldview-2, orto-photos, rational polynomial functions, pan-sharpening

\section{Introduction}

WorldView-2 (WV-2) was the most technologically-advanced high-resolution satellite ever launched before its twin, WorldView-3, reached orbit. The DigitalGlobe satellite was launched into space on October 8, 2009 from Vandenberg Air Force Base (CA) (Apollo Mapping, 2014).

On board of WV-2 satellite there are two types of sensors that, respectively, collects: panchromatic images $(0.450-0.800 \mu \mathrm{m})$ with cell size $0.46 \mathrm{~m}$ at nadir $(0.50 \mathrm{~m}$ for commercial uses) and multispectral images (Coastal

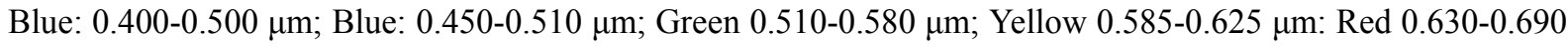
$\mu \mathrm{m}$; Red Edge 0.705-0.7 $45 \mu \mathrm{m}$; NIR1 0.770-0.895 $\mu \mathrm{m}$; NIR2 0.860-1.040 $\mu \mathrm{m}$ ) with cell size $1.84 \mathrm{~m}$ at nadir $(2$ $\mathrm{m}$ for commercial uses). Operating at an altitude of $770 \mathrm{~km}$ with an inclination of $97.2^{\circ}$, this sun synchronous satellite has an average revisit time of 1.1 days and is capable of collecting up to 1 million $\mathrm{km}^{2}$ of 8 -band imagery per day (Digital Globe, 2014).

Even if in the last ten years images from space with sub-meter spatial resolution have been available, these data are collected only in four spectral bands (generally named blue, green, red and infra-red), which makes the distinction of land cover classes a difficult task; with the launch of WV-2 for the first time ever, a high spatial resolution space-borne sensor with eight spectral bands ranging from blue to the near infrared parts of the electromagnetic spectrum has been operating, so the possibility to perform classification accuracy has been obtainable (Novack et al., 2011).

The high spatial resolution of WV2 images allows discrimination of a lot of details, such as vehicles and individual trees, while the high spectral resolution provides detailed information that facilitates the identification of a greater number of ground cover classes (e.g. more variety of vegetation) as well as the detection of changes 
in the use of the soil (Baiocchi et al., 2011). The integration of the classification maps derived by WV-2 with DTM that supplies the variability of the territorial morphology permits to produce 3D thematic models i.e. land cover (Maglione et al., 2014). Also vegetation parameter maps at high spatial resolution of $2 \mathrm{~m}$ ground sampling distance can be created from the 8-bands WV-2 imagery after the conversion of the BVs (Brightness Values) into surface reflectance (Borel, 2010). Applications of NDVI (Normalized Difference Vegetation Index) and NDWI (Normalized Difference Water Index) to WV-2 facilitate shoreline detection to monitor coastal erosion (Maglione et al., 2014).

The aim of this study is to demonstrate that WV-2 imagery can be used also to produce high resolution coloured ortho-photos: adequate positional accuracy is achieved using georeferencing process based on RPFs functions (Belfiore \& Parente, 2014) while cell size of panchromatic data $(0.5 \mathrm{~m})$ is transferred to multispectral ones by Pan-Sharpening (Parente \& Santamaria, 2013).

Production of orthophotos and maps with traditional methods is based on the use of aerial photograms (Crespi et al., 2003). This approach is very accurate, but each image covers a small terrain area (Kääb, 2002) and has other limitations, such as costs for the flight and data processing. These disadvantages can be limited using RGB resolution satellite images, which have reached sub-meter cell size and can be acquired repeatably for any zone with extensive area in each scene. More than the others WV-2 datasets are adequate for this purpose because the above mentioned combination of limited cell size dimensions and high number of bands that permits to achieve realistic RGB composition more similar to the natural human vision (Baiocchi et al., 2011).

This paper is organized as follows. In Section II the attention is focalized on data and methods: after a brief description of the study area and used dataset, the main characteristics of the georeferencing and Pan-Sharpening processes are summarized. In Section III results are shown and discussed. Section IV concludes the paper with general considerations.

\section{Data and Methods}

\subsection{Study Area and Dataset}

The study area is located in Caserta Province (Italy) (Figure 1). There is a complex landscape characterized by urban, industrial and agricultural zones. The different types of land use in a relatively small area render the territory particularly interesting to test the possibility to obtain realistic RGB composition by WV-2 for numerous natural as well as artificial features such as trees, buildings, roads.

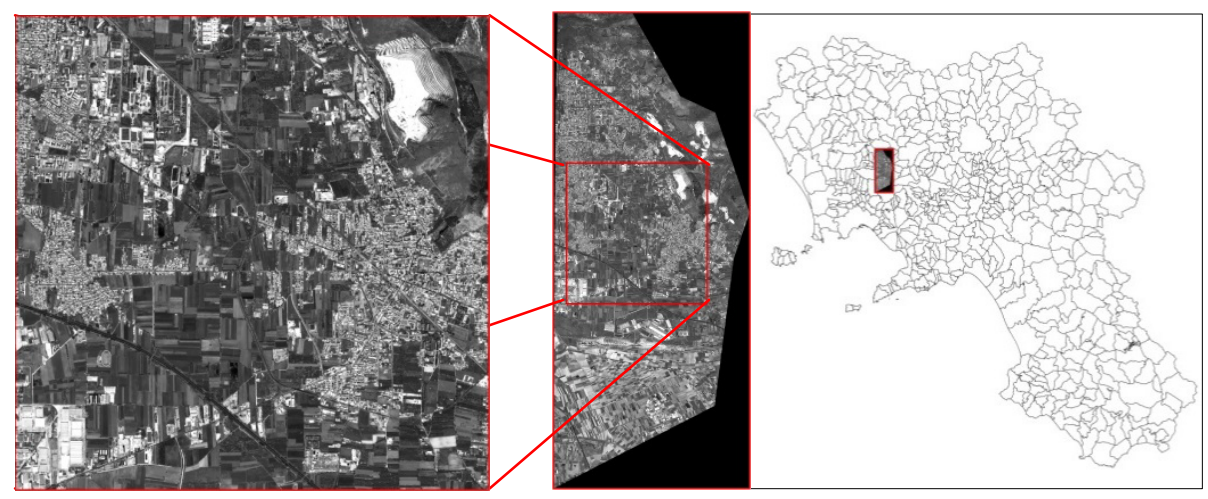

Figure 1. The study area within the Ortho Ready Standard WorldView-2 panchromatic image and its location in Campania Region (Italy)

For this application a complete set of WV-2 imagery (panchromatic as well as multispectral data) acquired on 08/10/2012 was used. The dataset was supplied by the vendors as Ortho Ready Standard product (DigitalGlobe, 2013), so it resulted already projected to a plane using a map projection (UTM, Universal Transverse of Mercator) and datum (WGS84), but without the variability of the elevation had been taken into account (the average terrain height established for the area of interest had been assumed as constant plane). In other words, the dataset was not ortho-rectified in the photogrammetric sense, so its geo-location was affected by errors. Overlay with orthophotos of Campania Region of the same area at scale 1:2,000 (pixel dimensions: $20 \mathrm{~cm}$ x 20 $\mathrm{cm})$ permitted to establish the planimetric accuracy of the whole scene: 20 Check Points (CPs) easily 
distinguished on the Pan image as well as on the orthophotos were considered and planimetric differences between rigorous cartographic and effective coordinates presented RMS $=15.53 \mathrm{~m}$ (Table 1). Because of the high resolution of the image, this positional accuracy was not acceptable, so a further process of geometric correction resulted necessary to increase it.

Table 1. Statistic values of errors (in meters) obtained for CPs in the original WorldView-2 panchromatic image

\begin{tabular}{cccccc}
\hline & Min & Max & Mean & St. Dev. & RMS \\
\hline CPs:20 & 2.23 & 42.21 & 11.27 & 10.68 & 15.53 \\
\hline
\end{tabular}

\subsection{Geometric Correction using Rational Polynomial Functions}

In Remote Sensing applications to improve the positional accuracy of the raw data two main categories of approaches are useful, named parametric and non-parametric methods. The first ones are based on rigorous models that use viewing geometry of the sensor (Parcharidis, 2005). Non-parametric methods are independent of the sensor characteristics as well as the acquisition mode and the most appropriate of them for high resolution satellite images are 3D Rational Polynomial Functions (RPFs) (Dowman \& Dolloff, 2000; Maglione et al., 2013). The relationship between image coordinates ( $\left.X^{\prime}, Y^{\prime}\right)$ and 3D object coordinates (X, Y, Z) is defined by (Toutin, 2004):

$$
X^{\prime}=\frac{P_{1}^{n}(X, Y, Z)}{P_{2}^{n}(X, Y, Z)} \quad Y^{\prime}=\frac{P_{3}^{n}(X, Y, Z)}{P_{4}^{n}(X, Y, Z)}
$$

where $P_{1}{ }^{n}, P_{2}{ }^{n}, P_{3}{ }^{n}, P_{4}{ }^{n}$ are usually cubic polynomials (with 20 coefficients for each of them). General polynomial can be expressed as:

$$
P_{l}^{n}(X, Y, Z)=\sum_{i=0}^{m_{1}} \sum_{j=0}^{m_{2}} \sum_{k=0}^{m_{3}} a_{l_{i j k}} X^{i} Y^{j} Z^{k}
$$

where:

$$
\begin{aligned}
& n=3 \\
& l=1,2,3,4 \\
& 0 \leq m_{1} \leq 3 ; \\
& 0 \leq m_{2} \leq 3 ; \\
& 0 \leq m_{3} \leq 3 ; \\
& m_{1}+m_{2}+m_{3} \leq 3
\end{aligned}
$$

To determine the values of the polynomial coefficients in equation 1 Ground Control Points (GCPs) which are identifiable in the image must be selected accurately on maps or other already corrected images to detect their coordinates. In the case $\mathrm{n}=3,78$ coefficients are present in equations 1 , so at least 39 GCPs must be considered, but a greater number is suitable to optimize transformation and reduce positional errors in the selected points. Rectification process was conducted on the panchromatic image (higher resolution) using PCI Geomatica OrthoEngine Version 2012. Then a clip was extracted and submitted to further process for colour orto-photos production.

\subsection{Pan-Sharpening}

Because multispectral images necessary for color composition (RGB) presented $2 \mathrm{~m}$ cell size, Pan-Sharpening process was introduced to grow out geometric resolution. Pan-Sharpening is a technique that can increase the potential of satellite imagery, which can be used for many applications requiring high spatial and high spectral resolution (Zhang, 2004). It permits to reduce the pixel dimensions of multispectral images to those of panchromatic ones. The resulted benefits are evident: more detailed coloured images (RGB composition) can be obtained and more accurate information becomes available for further applications such as classification, land cover and use mapping, features extractions and so on.

A large number of Pan-Sharpening methods are present in the literature (Amro et al., 2011), but they do not 
supply the same quality of the results (Parente \& Santamaria, 2013). Color distortions can be introduced and their effects are often evident when RGB composition is compared with that resulting by the original bands (Parente \& Santamaria, 2014): for this application Zhang method (Zhang, 1999) implemented in the software Focus by PCI Geomatics Enterprise was applied because of its high performance. No color distortions were evident in visual comparison, so the quality of the results was evaluated using some indexes that permitted a quantitative analysis of the performance of this method. Particularly the following ones based on comparison of statistical values of the input and output images were used:

- Correlation Coefficient (CC);

- Universal Image Quality Index (UIQI);

- ERGAS.

Correlation Coefficient $(\rho)$ is computed using the formula:

$$
C C_{X Y}=\frac{\operatorname{Cov}_{X Y}}{\sigma_{X} \sigma_{Y}}
$$

where:

$X$ is the input multispectral image;

$Y$ is the output (pan-sharpened) multispectral image;

$\operatorname{Cov}_{X Y}$ is the covariance between $\mathrm{X}$ and $\mathrm{Y}$ images;

$\sigma_{X}$ is the standard deviation of image $\mathrm{X}$;

$\sigma_{Y}$ is the standard deviation of image $\mathrm{Y}$.

Universal Image Quality Index (UIQI) is supplied by the formula (Wang \& Bovik, 2002):

$$
U I Q I_{X Y}=\frac{\operatorname{Cov}_{X Y}}{\sigma_{X} \sigma_{Y}} * \frac{2 \mu_{X} 2 \mu_{Y}}{\mu_{X}^{2} \mu_{Y}^{2}} * \frac{2 \sigma_{X} 2 \sigma_{Y}}{\sigma_{X}^{2} \sigma_{Y}^{2}}
$$

where:

$\mu_{\mathrm{X}}$ is the mean value of image $\mathrm{X}$;

$\mu_{Y}$ is the mean value of image $\mathrm{Y}$.

ERGAS (Erreur Relative Globale Adimensionelle de Synthèse) is calculated by the following formula (Wald, 2000):

$$
E R G A S=100 * \frac{h}{l} \sqrt{\frac{1}{N} \sum_{i=1}^{N} \frac{R M S E^{2}\left(B_{i}\right)}{M_{i}^{2}}}
$$

where:

$h$ is geometric resolution of the panchromatic image ( $0.50 \mathrm{~m}$ for the WV-2 imagery);

$l$ is the geometric resolution of the multispectral image ( $2 \mathrm{~m}$ for the WV-2 imagery).

The first two indexes (CC and UIQI) permit to compare each pan-sharpened image with the corresponding one from which it has been derived. The good quality of the result is characterized by values close to one for both $C C$ as well as UIQI. ERGAS is an example of global error parameter for describing the quality of the entire derived dataset. Nevertheless the mean value of CC (as well as of UIQI) can be assumed as global indicator of the Pan-Sharpening results. For RGB composition, cases of "good quality" exhibit ERGAS values less than 3, or slightly greater, while the error is larger than 3 for cases of "bad quality" (Wald, 2002).

\section{Results and Discussion}

Three different sets of GCPs (40, 50 and 60 GCPs) were considered for RPFs application: in all cases the same CPs (20) were used. GCPs and CPs are evidenced in Figure 2: their planimetric coordinates in UTM-WGS84 were derived from the above mentioned ortho-photos, while elevations were obtained by DEM available for the area (cell size: $20 \mathrm{~m}$ ). To evaluate the accuracy of the rectification process, the residuals obtained for GCPs as well as for CPs in XY direction were calculated. Statistic values of these errors are reported in Table 2 in reference to the considered models. 


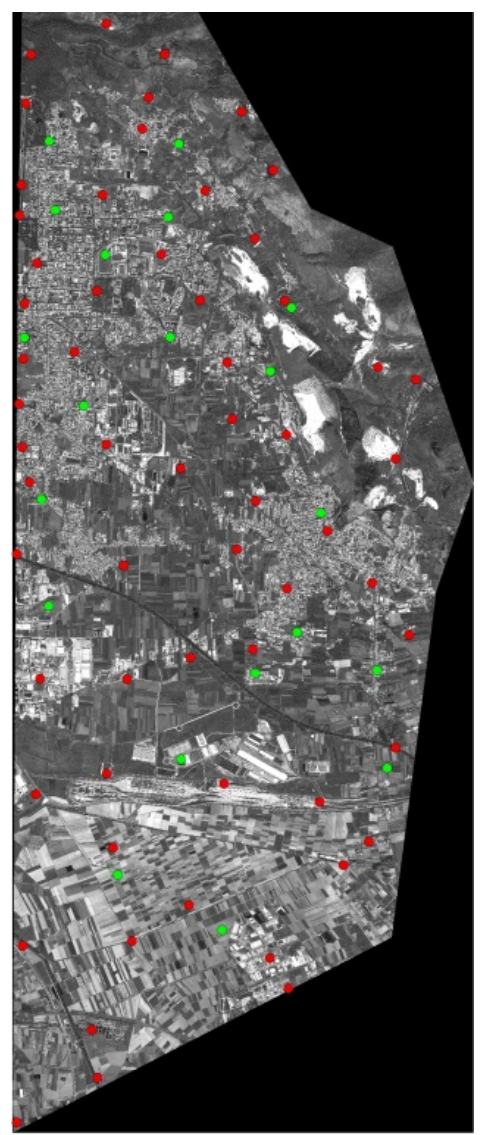

Figure 2. GCPs (in red) and CPs (in green) and their distribution on the WV-2 Panchromatic Image

Table 2. Statistic values of errors (in meters) obtained for GCPs and CPs by using RPFs

\begin{tabular}{lccccc}
\hline & Min & Max & Mean & St. Dev. & RMS \\
\hline GCPs: 40 & 0.01 & 1.08 & 0.37 & 0.26 & 0.45 \\
CPs:20 & 0.08 & 5.89 & 1.08 & 1.17 & 1.59 \\
GCPs: 50 & 0.01 & 1.23 & 0.40 & 0.27 & 0.48 \\
CPs:20 & 0.20 & 1.29 & 0.74 & 0.32 & 0.80 \\
GCPs: 60 & 0.04 & 1.09 & 0.43 & 0.25 & 0.50 \\
CPs:20 & 0.10 & 1.31 & 0.68 & 0.32 & 0.75 \\
\hline
\end{tabular}

The best positional accuracy was achieved with 60 GCPs: this model was used to rectify the entire dataset, panchromatic as well as multispectral images. As certified by the statistic values of the residuals in the $20 \mathrm{CPs}$, the orto-rectified imagery presented acceptable positional accuracy if compared with the smaller pixel dimension (panchromatic data: $0.5 \mathrm{~m}$ ). In fact, using RPFs with 60 GCPs the original errors were strongly reduced as certified by RMS of the residuals in CPs passed from $1.59 \mathrm{~m}$ to $0.75 \mathrm{~m}$. Probably better results can be achieved using the photogrammetric approach or increasing the quality of the GCPs and CPs carrying out their coordinates from GNSS survey. Nevertheless the achieved products can be considered of high quality.

About the results of the Pan-Sharpening process, the values obtained for the above mentioned indexes are reported in Table 3: they confirm the high performance of the Zhang method, so the pan-sharpened images can be considered similar to those that should have been obtained by multispectral sensor with the same geometric resolutions of the panchromatic one.

For the considered scene, coloured aerial image, WV-2 panchromatic image, RGB composition with original 
multispectral images, the resulting coloured orto-photo are reported, respectively, in Figures 3, 4, 5, 6. Details of them are reported in Figures 7, 8, 9, 10.

Table 3. The results achieved with the different indexes to evaluate SVR Zhang method.

\begin{tabular}{ccc}
\hline $\mathrm{CC}(\rho)$ & UIQI & ERGAS \\
\hline 0.95 & 0.95 & 3.09 \\
\hline
\end{tabular}

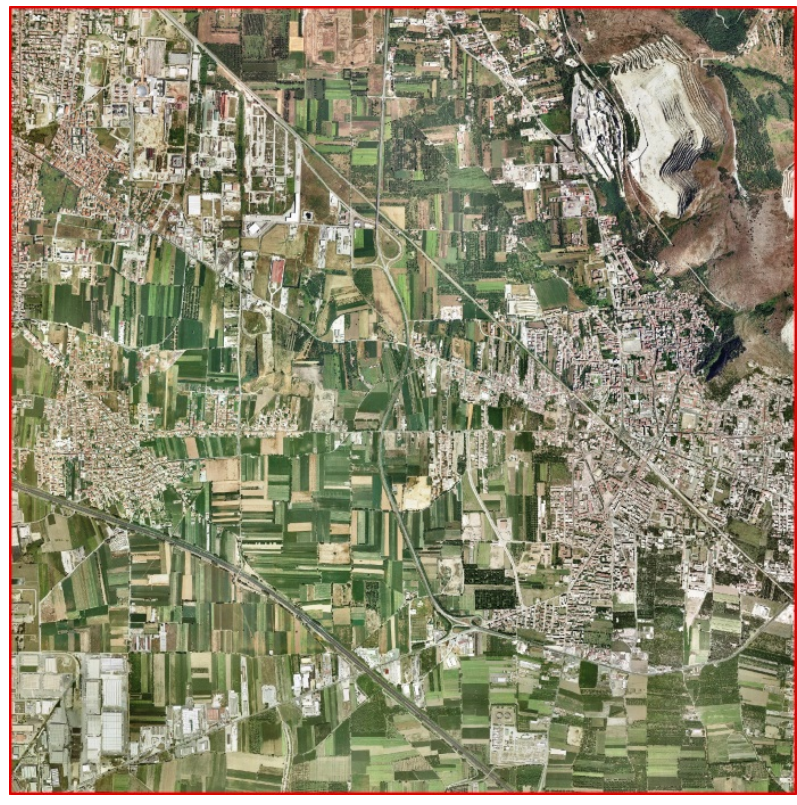

Figure 3. Coloured Aerial image

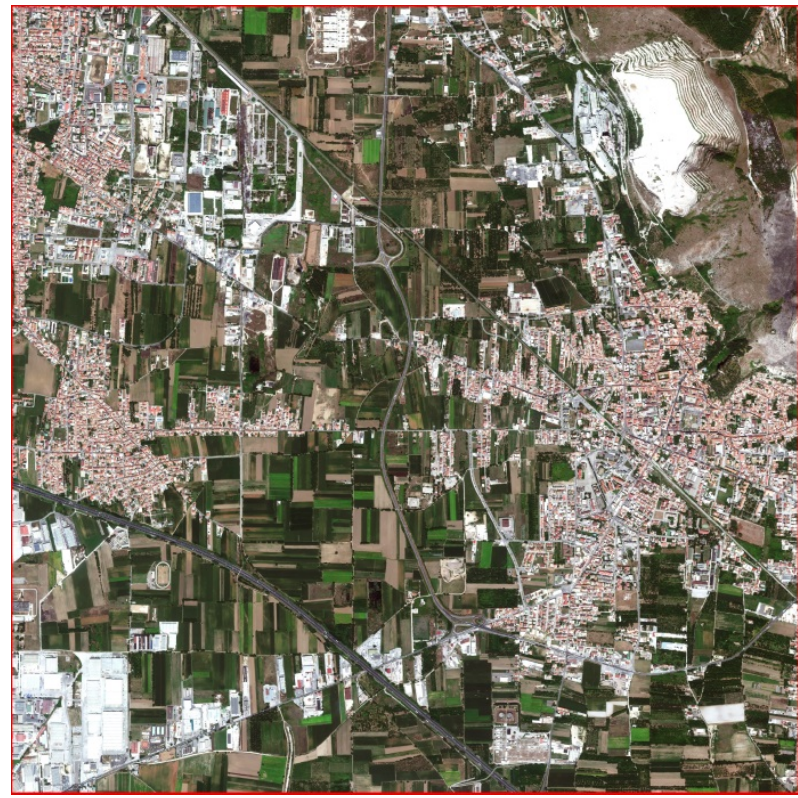

Figure 5. RGB composition with WV-2 original multispectral images

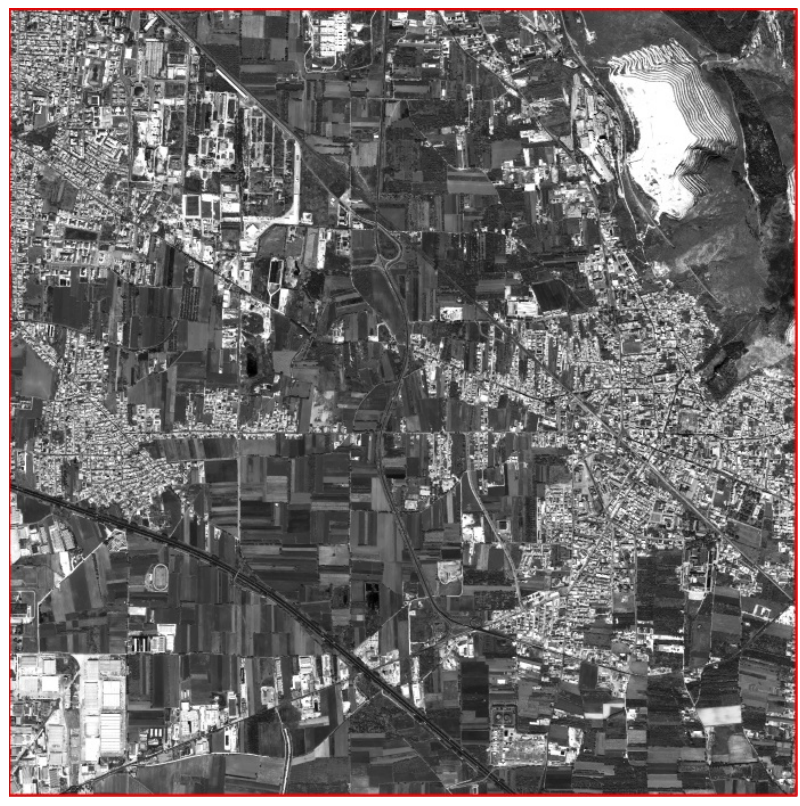

Figure 4. WV-2 Panchromatic image

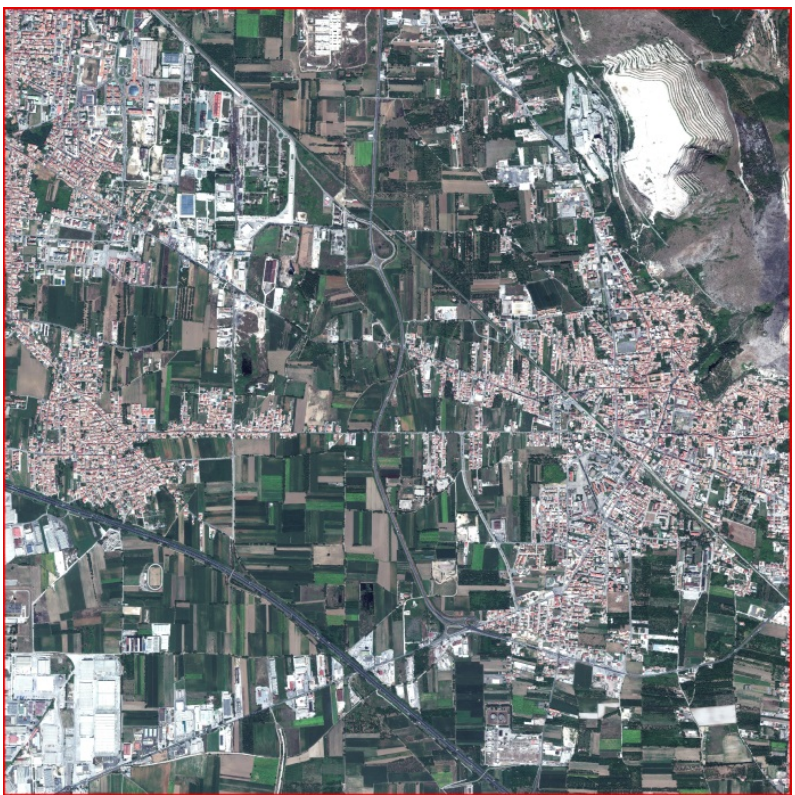

Figure 6. RGB composition with WV-2 pan-sharpened multispectral images 


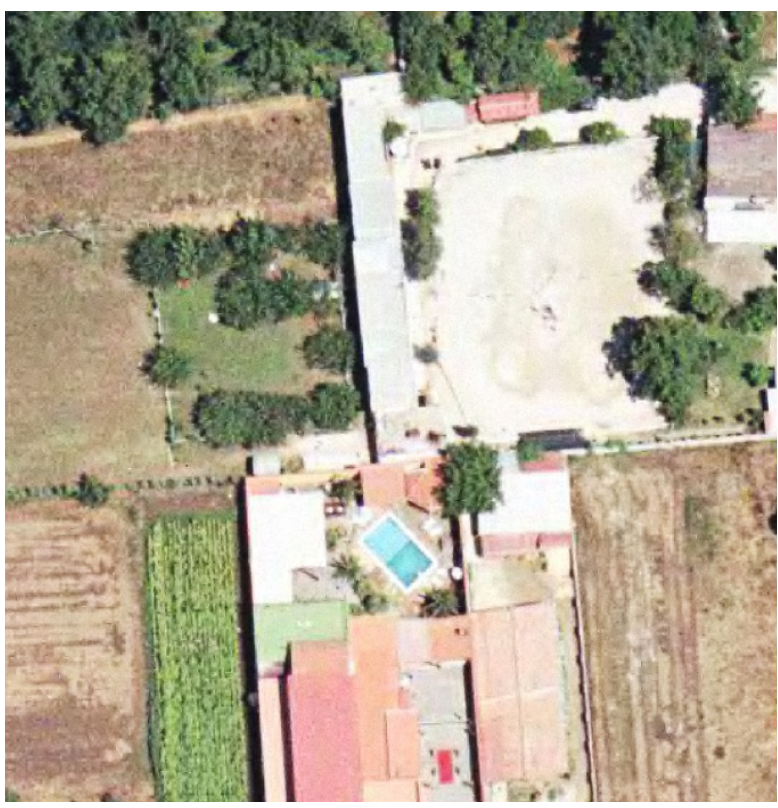

Figure 7. Details in the coloured aerial image

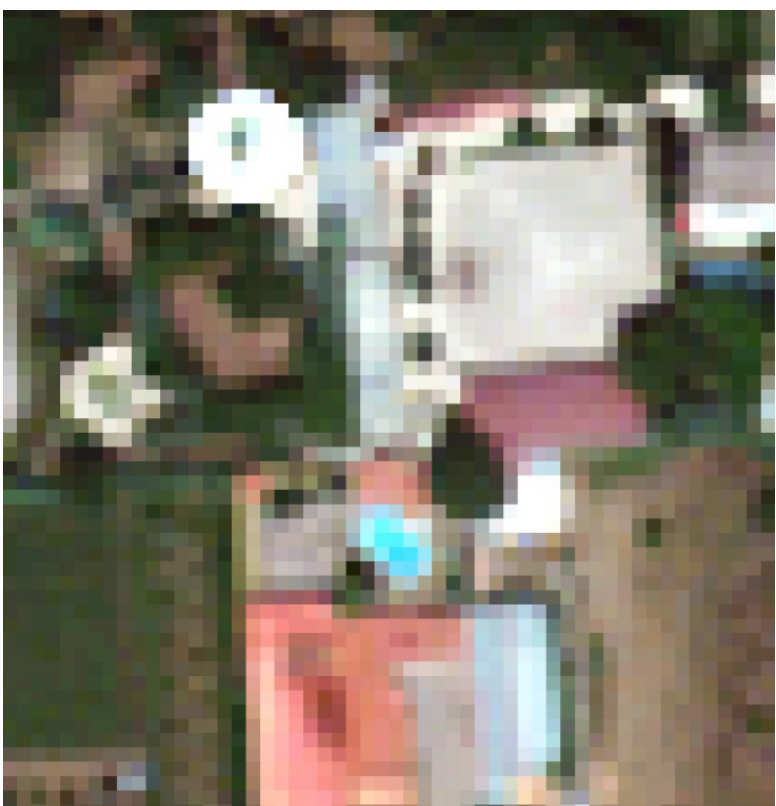

Figure 9. Details in RGB composition with WV-2 original multispectral images

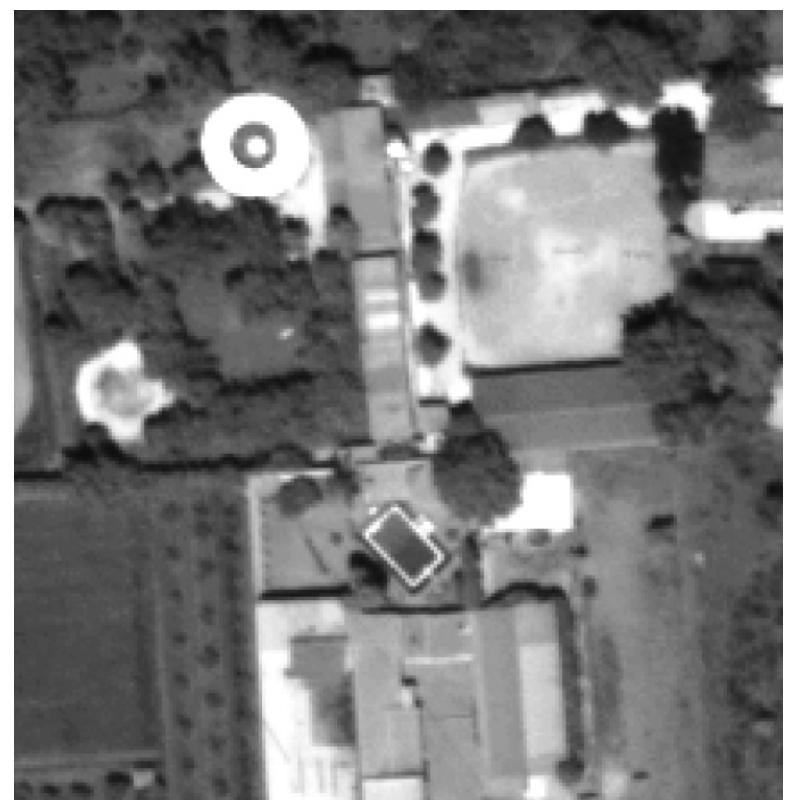

Figure 8. Details in WV-2 Panchromatic image

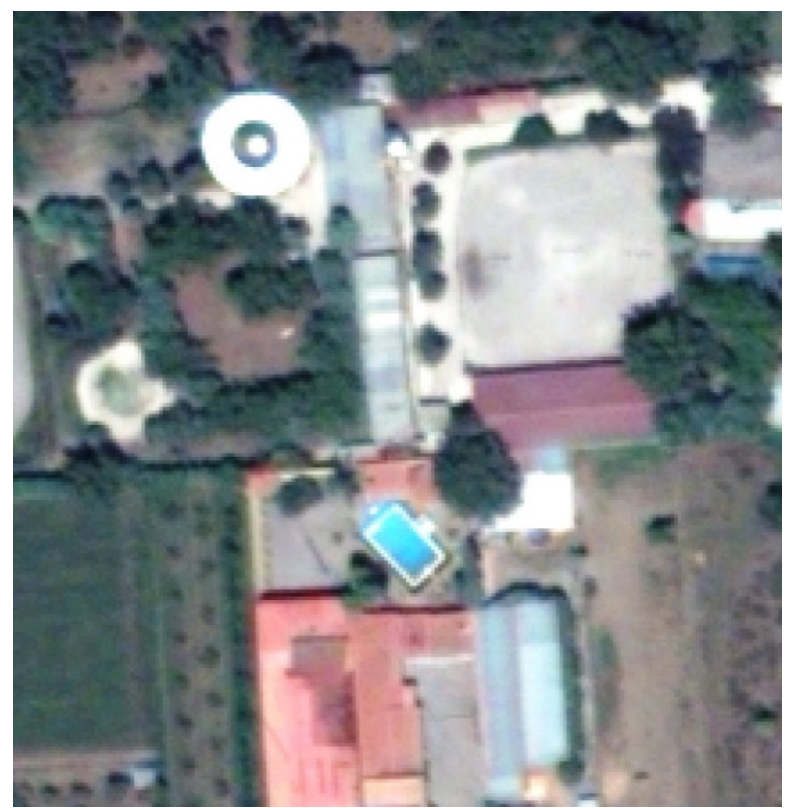

Figure 10. Details in RGB composition with WV-2 pan-sharpened multispectral images

\section{Conclusion}

The experiments carried out confirm that WV-2 imagery can be used for the production of coloured orto-photos with high geometric resolution. In fact from it products with adequate positional accuracy and cell size of $0.5 \mathrm{~m}$ can be derived. About the first aspect, further geometric corrections must be applied to the traditional Ortho Ready Standard product: RPFs with GCPs (the number of them depends by the morphology of the territory) permit to reduce positional errors carrying them to values proxime to the pixel dimension.

About the orto-photos cell size equal to $0.5 \mathrm{~m}$, this goal can be achieved with WV-2 imagery using Pan-Sharpening process: the affidability of the results in term of absence of significative color distortion can be tested using not only visual analysis, but also quality indexes that are present in literature. 
The advantages that result from WV-2 imagery use for orto-photos instead of the traditional dataset by airplane with the same geometric resolution are evident: less expensive costs, greater area for each scene, more availability of data.

\section{Acknowledgments}

This paper synthesizes results of works performed within the project PRIN 2010-11 financed by MIUR (Ministero dell'Istruzione, dell'Università e della Ricerca), the Italian Ministry of Instruction, University and Research, and developed at the University of Naples "Parthenope" (Coordinator: Prof. Raffaele Santamaria).

\section{References}

Amro, I., Mateos, J., Vega, M., Molina, R., \& Katsaggelos, A. K. (2011). A survey of classical methods and new trends in pansharpening of multispectral images. EURASIP Journal on Advances in Signal Processing. Springer Open Journal, 79. Retrieved from http://asp.eurasipjournals.com/content/2011/1/79

APOLLO MAPPING-The ImageHunter (2014). Retrieved October 17, 2014, from https://apollomapping.com/imagery/high-resolution-imagery/worldview-2

Baiocchi, V., Brigante, R., Dominici, D., \& Radicioni, F. (2011), Coastline detection using high resolution multispectral satellite images. FIG Working Week 2012, Knowing to manage the territory, protect the environment, evaluate the cultural heritage, Rome, Italy, 6-10 May 2012.

Belfiore, O. R., \& Parente, C. (2014). Comparison of Different Methods to Rectify IKONOS Imagery without Use of Sensor Viewing Geometry. American Journal of Remote Sensing, 2(3), 15-19. http://dx.doi.org/10.11648/j.ajrs.20140203.11

Borel, C. C. (2010). Vegetative canopy parameter retrieval using 8-band data. DigitalGlobe 8-Band Resarch Challenge. Retrieved from https://www.exelisvis.com/portals/0/pdfs/envi/8_bands_Christoph_Borel.pdf

Crespi, M., Baiocchi, V., De Vendictis, L., \& Lorenzon, F. (2003). Impiego cartografico di immagini satellitari ad alta risoluzione-le problematiche metriche: dati primari, metodologie, sperimentazioni. La cartografia per il controllo e la gestione del territorio. Atti del Convegno (Lamezia Terme 2003).

Digital Globe (2013). DigitalGlobe Core Imagery Products Guide. Retrieved October 17, from http://www.geosoluciones.cl/documentos/worldview/DigitalGlobe-Core-Imagery-Products-Guide.pdf

DigitalGlobe (2014). DATA SHEET. Retrieved October 17, 2014, from http://www.digitalglobe.com/sites/default/files/DG_WorldView2_DS_PROD.pdf

Dowman, I., \& Dolloff, J. T. (2000). An evaluation of rational functions for photogrammetric restitution. International archives of photogrammetry and remote sensing, 33(B3/1; PART 3), 254-266.

Kääb, A. (2002). Monitoring high-mountain terrain deformation from repeated air-and spaceborne optical data: examples using digital aerial imagery and ASTER data. ISPRS Journal of Photogrammetry and Remote Sensing, 57(1), 39-52.

Maglione, P., Parente, C., Santamaria, R., \& Vallario, A. (2014). Modelli tematici 3D della copertura del suolo a partire da DTM e immagini telerilevate ad alta risoluzione WorldView-2. Rendiconti Online della Società Geologica Italiana, 30, 33-40. http://dx.doi.org/10.3301/ROL.2014.08

Maglione, P., Parente, C., \& Vallario, A. (2013). Using Rational Polynomial Functions for rectification of GeoEye-1 imagery, IOSR Journal of Applied Geology and Geophysics, 1(6), 11-17. e-ISSN: 2321-0990, p-ISSN: 2321-0982. http://dx.doi.org/10.9790/0990-0161217

Maglione, P., Parente, C., \& A. Vallario (2014). Coastline extraction using high resolution WorldView-2 satellite imagery. European Journal of Remote Sensing, 47, 685-699. http://dx.doi.org/10.5721/EuJRS20144739

Novack, T., Esch, T., Kux, H., \& Stilla, U. (2011).Machine Learning Comparison between WorldView-2 and QuickBird-2-Simulated Imagery Regarding Object-Based Urban Land Cover Classification. Remote Sensing, 3, 2263-2282.

Parcharidis, I., Foumelis, M., Papageorgiou, E., Segou M., \& V. Sakkas, V. (2005). Orthorectification and assessment of QuickBird imagery using D-GPS measurements over Paros urban area. In Proceedings of the International Society for Photogrammetry and Remote Sensing 2005, Joint Conference.

Parente, C., \& Santamaria. R. (2013). Increasing Geometric Resolution of Data Supplied by Quickbird Multispectral Sensors. Sensors and transducers, 156, 9/13, ISSN 1726-5479.

Parente, C., \& Santamaria. R., (2014). Synthetic Sensor of Landsat 7 ETM+ Imagery to Compare and Evaluate 
Pan-sharpening Methods, Sensors and transducers, 177(8), 294-301. ISSN 1726-5479.

Wald, L. (2000). Quality of high resolution synthesised images: Is there a simple criterion? In Proceedings, 99-103.

Wald, L. (2002). Data Fusion. Definitions and Architectures - Fusion of Images of Different Spatial Resolutions. Presses de l'Ecole, Ecole des Mines de Paris, Paris, France, ISBN 2-911762-38-X, 200.

Wang, Z., \& Bovik, A. C. (2002). A universal image quality index. Signal Processing Letters, IEEE, 9(3), 81-84.

Zhang, Y. (1999). A new merging method and its spectral and spatial effects. International Journal of Remote Sensing, 20(10), 2003-2014. http://dx.doi.org/10.1080/014311699212317

\section{Copyrights}

Copyright for this article is retained by the author(s), with first publication rights granted to the journal.

This is an open-access article distributed under the terms and conditions of the Creative Commons Attribution license (http://creativecommons.org/licenses/by/3.0/). 